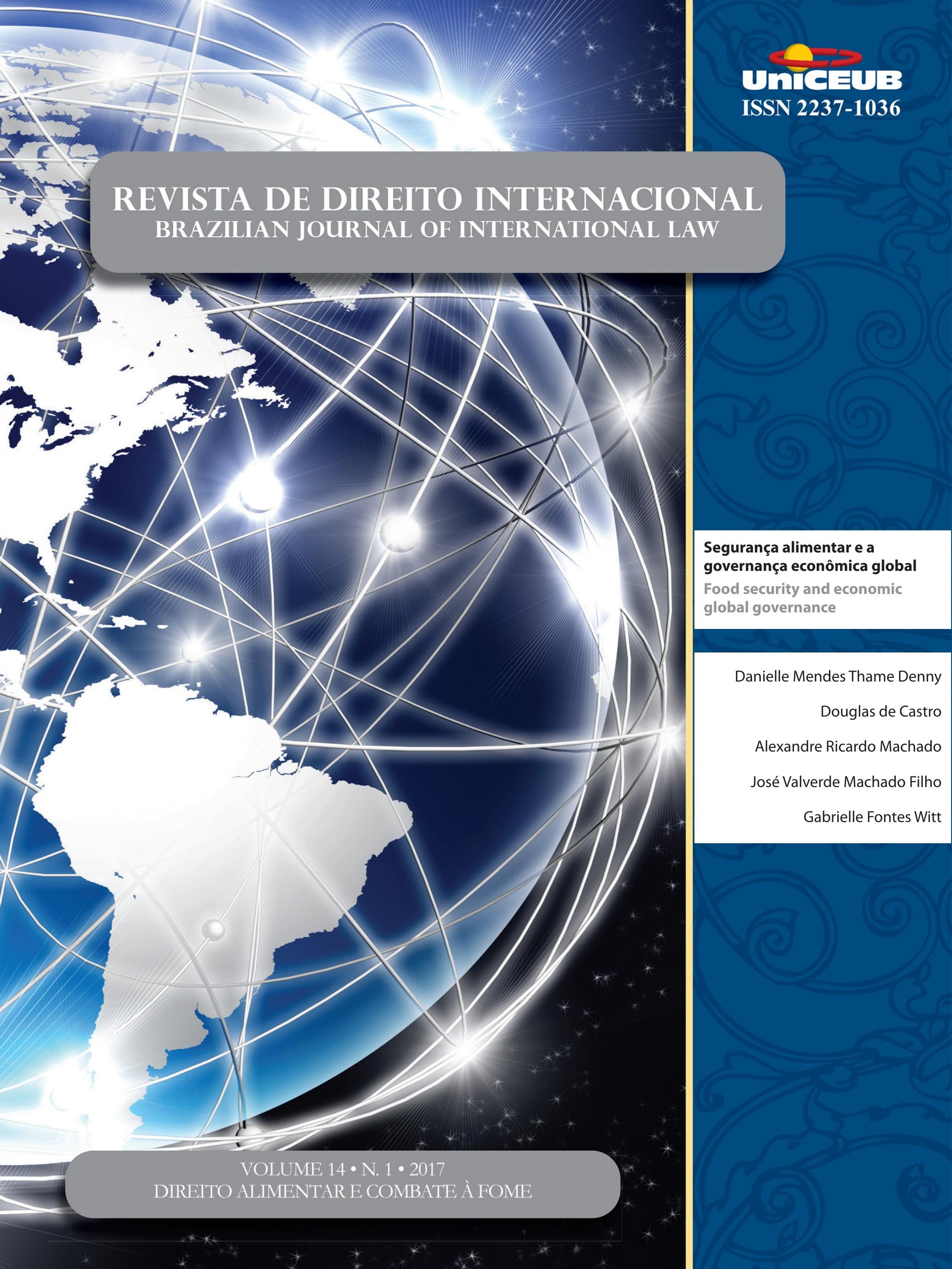




\section{Sumário}

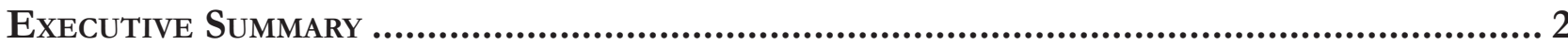

Daniel Balaban

Crônicas Sobre o Direito Alimentar e o Combate À Fome .............................................. 5

South-South Food and Nutrition Security promotion: the Brazilian experience

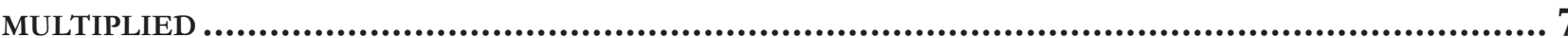

João Almino

Access to Food as a Human Right: Brazil, WFP and South-South Cooperation .......10 Carlos R. S. Milani

Dossiê temático: Direito Alimentar e Combate à Fome 13

WFP'S ROLE IN BUILDING SUSTAINABLE BRIDGES BETWEEN THE RIGHT TO ADEQUATE FOOD AND THE FREEDOM FROM HUNGER 15

Christiani Amaral Buani e Bruno Valim Magalhães

Direito humano À ALIMENTAÇÃo, (IN) SEgURANÇA ALIMENTAR E DESENVOLVIMENTO: OS DESAFios à REALIZAÇão PROGRESSIVA Na AMÉrica LATINa

Sinara Camera e Rubia Wegner

STATE'S INTERNATIONAL RESPONSIBILITY FOR THE HUMAN RIGHT TO FOOD: IMPLEMENTATION IN BRAZIL THROUGH AGROECOLOGY

Paula F. Strakos e Michelle B.B. Sanches

NegotiatiNg agRiCULtURE IN THE WORLD TRADE ORgANIZATION: FOOD SECURITY AS A NON-TRADE CONCERN.

Ana Luísa Soares Peres e Letícia de Souza Daibert

QUANDO HABITAR CORRESPONDE AO DIREITO HUMANO À ALIMENTAÇÃO

Fernanda Viegas Reichardt e Maria Elisa de Paula Eduardo Garavello 
The ROLE OF SUSTAINABLE LEARNING POLICIES ON THE FIGHT AGAINST

HUNGER IN ADULT EDUCATION.

Hiran Catuninho Azevedo

O DIREITO HUMANO E FUNDAMENTAL À ALIMENTAÇÃo ADEQUADA E À CONDIÇÃo

FEMININA NO PROGRAMA BOLSA FAMÍlIA: EMPODERAMENTO ÀS AVESSAS?

Rosalice Fidalgo Pinheiro e Laura Garbini Both

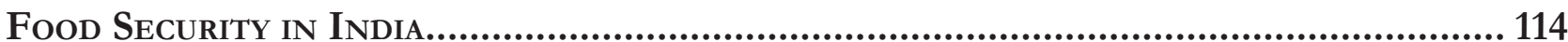

Ranjana Ferrão

SEguranÇA ALIMENTAR E A GOVERnANÇA ECONÔMICA GLOBAL

Danielle Mendes Thame Denny, Douglas de Castro, Alexandre Ricardo Machado, José Valverde Machado Filho e Gabrielle Fontes Witt

Outros Artigos.

The legal implications of the Draft Universal Declaration of the Rights of MANKIND

Catherine Le Bris

Litigating Indigenous Dispossession in THE Global Economy:

Law's Promises and Pitfalls................................................................................ 165

Charis Kamphuis

UNE DÉFINITION DU PRÉ-INVESTISSEMENT CONFORME À L'APPROCHE FRANÇAIS MAIS CONTRAIRE À L'APPROCHE AMÉRICAINE AU SEIN DES TRAITÉS BILATÉRAUX D'INVESTISSEMENTS IRANIENS

Peyman Dadras

CONFLITOS ENTRE REGULAÇÕES INTERNAS RELATIVAS À INTERNET E O DIREITO DO COMÉRCIO INTERNACIONAL: O PAPEL DA OMC PERANTE O SISTEMA DE COMPUTAÇÃO DA NUVEM ............238

Alice Rocha da Silva e Filipe Rocha Martins Soares

Prélèvement: origem, EVoluÇão e ocaso do Privilégio NAS SuCESSÕes INTERNACIONAIS NA FRANÇA

Fernando Pedro Meinero 
OS CONTRATOS INTERNACIONAIS DE FINANCIAMENTO E O CENTRO FINANCEIRO DE

Nova IorQue: CONSIDERAÇões SOBRE A AUTONOMIA DA VONTADE

Fernanda Torres Volpon

Mercosul e o Meio ambiente: ANÁlise da tUTELA REgional AMBIENTAL 284 Clarissa Ferreira Macedo D'Isep

Ainda (E uma Vez MAis) o SILÊNCIO QUe ENTOA O TRIUNFo De Lewis Carrol: A Regra N ${ }^{\circ} 42$ do Supremo Tribunal Federal

Thiago Aguiar Pádua e Bruno Amaral Machado

\section{A Natureza Jurídica do Sistema de Solução de Controvérsias da OMC} E DE SuAs Decisões: Solucionando um Imbróglio 316

Camila Capucio

Brics: Desafios do DESENVOLVIMENTO ECONÔMICO E SOCIOAMBIENTAI Magno Federici Gomes e Luís Eduardo Gomes Silva

REVER OU ROMPER COM VESTFÁLIA? POR UMA RELEITURA DA EFETIVA CONTRIBUIÇÃO DOS ACORDOS DE PAZ DE 1648 À CONSTRUÇÀO DO MODELO VESTFALIANO DE ESTADOS.

Luiz Magno Pinto Bastos Junior

Justiça de Transição EM SUA GÊNESE: A Alemanha Pós-NAZismo 378 Bruno Galindo

Quando JUlgar SE TORNa UM ESPETÁCulo: A INTERAÇão ENTRE o Supremo Tribunal Federal e a opinião pública, A PARTIR de REFlexões da LITERATURA ESTRANGEIRA

Patrícia Perrone Campos Mello

TolerânCia E refugio: um ENSAIO A PARTIR do ACORdo EU-TurQuia 425 Flávia Cristina Piovesan e Ana Carolina Lopes Olsen 


\title{
Segurança alimentar e a governança econômica global*
}

\section{Food security and economic global governance}

\author{
Danielle Mendes Thame Denny** \\ Douglas de Castro*** \\ Alexandre Ricardo Machado**** \\ José Valverde Machado Filho ${ }^{* * * * *}$
}

Gabrielle Fontes Witt ${ }^{* * * * *}$

* Recebido em 31/10/2016

Aprovado em 01/05/2017

** Pesquisadora Visitante no Whitney and Betty MacMillan Center for International and Area Studies na Universidade Yale, EUA. Doutoranda em Direito Ambiental Internacional na Universidade Católica de Santos, com bolsa da Coordenação de Aperfeiçoamento de Pessoal de Nível Superior. Professora na Fundação Armando Alvares Penteado e na Universidade Paulista. E-mail: danielle.denny@gmail.com

*** Pós-doutorando da Escola de Direito de São Paulo da Fundação Getulio Vargas. Doutor em Ciência Política - Relações Internacionais pela Faculdade de Filosofia, Letras e Ciências Humanas da Universidade de São Paulo. Mestre em Direito pela Faculdade de Direito da Universidade de São Paulo. LL.M. em Direito Internacional pela Brigham Young University. E-mail: douggcastro@gmail.com

**** Doutorando em Direito Ambiental Internacional na Universidade Católica de Santos, com bolsa da Coordenação de Aperfeiçoamento de Pessoal de Nível Superior. Professor na Faculdade de Tecnologia Rubens Lara - Baixada Santista. Diretor da Alexandre Machado Consultoria Estratégica de Negócios. E-mail: alexandre@alexandremachado.com.br

***** Mestre em Direito Ambiental na Universidade Católica de Santos. Secretário executivo do Conselho Estadual de Segurança Alimentar e Nutricional do Estado de São Paulo. E-mail: josevalverdefilho@gmail.com

****** Bacharel em Relações Internacionais pelo Centro Universitário Ritter dos Reis, Porto Alegre, RS. E-mail: gabriellefwitt@gmail.com

\section{Resumo}

O presente artigo tem o objetivo de fazer uma análise da segurança alimentar sob a ótica do Direito Econômico Internacional. Primeiro discorre sobre as causas da insegurança alimentar, em seguida faz um histórico global e brasileiro, contextualizando a questão no Direito Econômico Ambiental Internacional e na defesa dos Direitos Humanos, para, por fim, tratar da problemática sob a perspectiva da governança global. A conclusão principal do trabalho é que a insegurança alimentar vem sendo causada pela má distribuição e não por falta propriamente de alimentos e que as ferramentas de governança global para coordenar interesses antagônicos na busca do objetivo comum da erradicação da fome têm muito a melhorar. A metodologia escolhida foi a análise qualitativa com pesquisa documental, legislativa e bibliográfica.

Palavras chave: Segurança Alimentar, Objetivos do Desenvolvimento Sustentável, Governança Global

\section{Abstract}

This article analyses food security mainly from the Economic International Law perspective. First, it brings the causes of food insecurity, then the global and Brazilian history to contextualize the issue using International Environmental Law, Economic Law as well as Human Rights, to finally address the problem using the lens of global governance. The main argument of this paper is that food insecurity is being caused by misdistribution rather than by lack of food, and that the tools of global governance to coordinate conflicting interests in pursuit of the common goal of hunger eradication have much to be improved. The methodology used was the qualitative analysis with documental, legislative and bibliographic research.

Key words: Food Security, Sustainable Development Goals, Global Governance 


\section{INTRODUÇÃO}

A fome é um problema de ordem mundial e nenhuma nação está imune a esta dificuldade, nem mesmo os países mais desenvolvidos. ${ }^{1}$ Com o avanço tecnológico nos meios de produção, o problema deixa de ser de produtividade insuficiente e passa a se concentrar na má distribuição, na sonegação alimentar e no desperdício. Além disto, outro problema é o fato de que a cadeia alimentar humana está nas mãos de grandes corporações que dominam o destino dos recursos gerados. Uma consequência disso foi o anúncio realizado em junho de 2009, após o aumento dos preços dos alimentos e da crise internacional de 2007-2008, em que o número de pessoas com fome no mundo chegou ao recorde histórico de 1,02 bilhão de pessoas. ${ }^{2}$

A insegurança alimentar tem sido um problema recorrente ao longo da história e, sem dúvida, a fome tem sido manifestada devido a um conjunto de fatores e em certos locais, por quebras de safra, pragas, guerras e conflitos, epidemias ou pelo aumento da população. ${ }^{3}$ A perda de colheitas, pragas e a explosão populacional não foram abordadas de forma eficaz e nos últimos 20 anos têm-se acrescentado outras causas potenciais de insegurança alimentar, na medida em que seu alcance não é agora apenas local, mas potencialmente mundial.

As tentativas de aumentar a segurança alimentar esbaram em dois grandes problemas que estão relacionados: o primeiro deles é o atual modelo do sistema internacional alimentar que está baseado em monoculturas altamente dependentes de agrotóxicos e sementes transgênicas (GMOs), cuja produção está voltada para a exportação; o segundo é que os principais atores neste sistema são as empresas transnacionais (ETNs), cuja finalidade precípua não é a erradicação da fome, mas a geração de lucros. Estas são duas variáveis intervenientes importantes na análise das iniciativas adotadas pelas organizações intergovernamentais e não-governamentais que buscam dar respostas ao problema da fome no mundo.

1 KEARNS, Antony P. The Right to Food Exist via Customary Internacional Law. Suffok Transnational Law Review. Vol.22, n.1, pp. 223-257,1998-1999.

2 COSTA, Claudia V.; BEGNIS, Heron Sergio M. Revista de Economia \& Relações Internacionais. Fome mundial: uma análise de suas causas e da atuação da FAO. Vol. 12(24), pp. 44-60, 2014.

3 PEARSON, Craig. A fresh look at the roots of food insecurity. In: RAYFUSE, Rosemary; WEISFELT, Nicole (Orgs.). The challenge of food seccurity: internacional policy and regulatory frameworks. Cheltennham, UK: Edward Elgar, 2012.
Desse modo, a comodificação dos alimentos que ocorre a partir da adoção do modelo da monocultura está no centro do debate sobre a segurança alimentar, pois coloca o debate entre os dois paradigmas: um centrado no mercado global voltado à exportação, cujo objetivo principal não é a erradicação da fome e que coloca em perigo a biodiversidade; e outro voltado para a produção e distribuição no mercado local, que preserva a biodiversidade e protege o conhecimento tradicional da agricultura familiar. ${ }^{4}$ Reforçando esse argumento com um aporte teórico mais robusto em relação ao segundo paradigma, Shaw sintetiza:

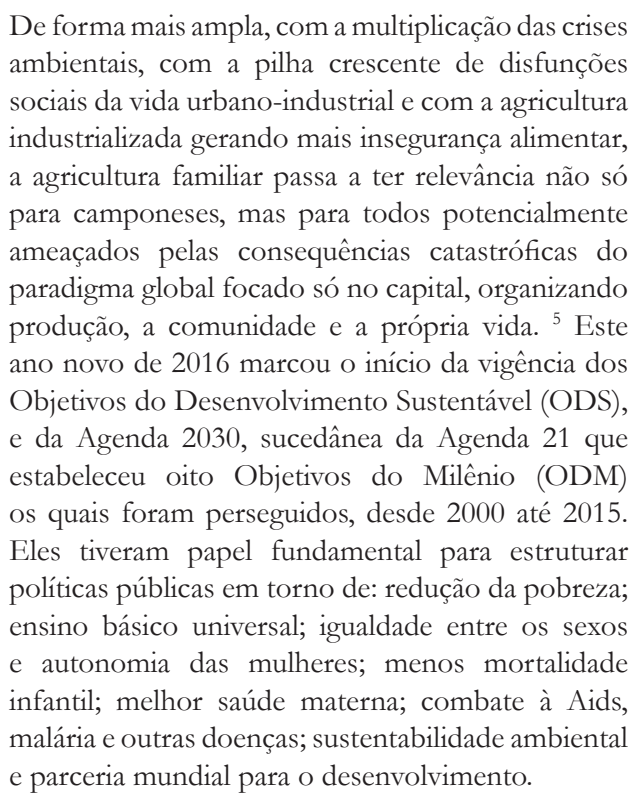

Para atingir esses objetivos, a Organização das Nações Unidas trabalhou, até o ano passado, com um conjunto de 18 metas, monitoradas por 48 indicadores. Essas metas decorriam da Declaração do Milênio, o mais importante compromisso internacional em favor do desenvolvimento e da eliminação da pobreza e da fome no mundo, assinada em setembro de 2000, por representantes de 191 estados membros da ONU, incluindo 147 chefes de Estado. Já a primeira dessas metas era reduzir pela metade os casos de extrema pobreza e desnutrição.

4 SHIVA, V. Monoculturas Da Mente. Perspectivas Da Biodiversidade E Biotecnologia. São Paulo: Gaia, 2003; CARSON, R. Primavera silenciosa. Editora Gaia, 2015.

5 Tradução livre do trecho: "More broadly, as environmental crises multiply, as the social dysfunctions of urban-industrial life pile up, and as industrialized agriculture creates greater food insecurity, the "peasant way" has relevance not only to peasants but to everyone threatened by the catastrophic consequences of global capital's vision for organizing production, community, and life itself." SHAW, D. World Food Security: A History since 1945. 2007 edition ed. Basingstoke England ; New York: Palgrave Macmillan, 2007. 
O relatório da ONU, intitulado The Millennium Development Goals Report ${ }^{6}$ demonstrou que a maioria dos países, inclusive o Brasil, conseguiu alcançar ou se aproximar dessas metas, o que reforça o argumento da eficácia desses instrumentos de soft law, que mesmo não prevendo sanções por descumprimento, têm capacidade de gerar comprometimento e cooperação dos países em busca de resultados. No caso especificamente da primeira meta o resultado foi bastante expressivo, três anos antes do prazo já se havia superado a meta, chegando a dois terços de erradicação de pobreza. No tocante à desnutrição ficou muito próxima, ela atingia $23.3 \%$ da população dos países em desenvolvimento em 1992 e caiu para $12.9 \%$ em 2014, isso corresponde a $45 \%$ de queda, quase alcançada a meta de redução pela metade, portanto.

Porém, por outro lado, o mesmo relatório deflagrou o quanto ainda há para ser alcançado, mais de 800 milhões de pessoas ainda estão malnutridas, o saneamento básico ainda não chegou para quase um terço da população do mundo e a extrema pobreza tem matado na última década o triplo do que a Segunda Guerra Mundial7. Há um déficit massivo na efetivação de direitos humanos, tanto dos civis e políticos, como dos econômicos, sociais e culturais.

Os principais desafios são enfrentados por países com menor desenvolvimento relativo. E uma das razões é o financiamento, enquanto países industrializados chegam a arrecadar 50 mil dólares por pessoa, países menos desenvolvidos como a Índia nem chegam a duzentos dólares. ${ }^{8}$ Assim a capacidade desses países para financiar medidas para implementar os ODS fica de antemão prejudicada.

Além disso, nos países de menor desenvolvimento relativo a capacidade de aumentar essa arrecadação é limitada. A tributação sobre o consumo tem uma ca-

6 ONU. The Millennium Development Goals Report. 2015. Disponível em: < http://www.un.org/millenniumgoals/2015_MDG_ Report/pdf/MDG\%202015\%20rev\%20(July\%201).pdf > Acesso em 10 de outubro de 2016.

7 "poverty and undernourishment cause some 18 million painful deaths each year, some 450 million during the MDG period, while the entire Second World War caused 'only' around 60 million deaths. This estimate is based on the WHO's classification of deaths by cause, counting as poverty-related all those death causes that are essentially confined to the poor countries. When almost no one dies of diarrhea in the affluent countries and millions die from diarrhea in poor countries, then I assume that diarrhea is a poverty-related cause and diarrhea deaths are poverty-related. I use the WHO's data for 2004 as this year is roughly in the middle of the MDG period." POGGE, Tomas. The Hunger Games. Food ethics (2016) 1: 9. June 2016, Volume 1, Issue 1, pp 9-27

8 POGGE, Thomas e MEHTA, Krishen. Global tax fairness. Nova York: Oxford University Press, 2016, p. 291. racterística de não proporcionalidade, fazendo com que os mais pobres paguem mais tributos e as tributações sobre a renda e patrimônio costumam ser evadidas ou elididas por esquemas ou planejamentos tributários que tendem a reverter recursos para fora desses países.

Assim, o aspecto econômico e financeiro precisa também ser levado em consideração, junto com a análise ambiental e social. Desse modo, o presente artigo visa contribuir com a análise transdisciplinar das causas que promovem a insegurança alimentar e as suas implicações nas dimensões internacional e nacional, bem como seus desdobramentos no Direito Econômico e as contribuições do direito para a solução do problema da fome a partir do marco conceitual da governança. A metodologia escolhida foi a análise qualitativa com pesquisa documental, legislativa e bibliográfica.

\section{Causas estruturais da insegurança ALIMENTAR}

Josué de Castro, em seu livro Geografia da Fome - O dilema brasileiro: pão on aço ${ }^{9}$, aponta que a fome é um fenômeno recorrente de natureza social e natural que recebe pouca atenção da academia e constrange a sociedade. Como se pode ver do gráfico a seguir, esta afirmação feita da década de 1960 é verdadeira e somente passa a fazer parte das discussões acadêmicas a partir das crises alimentares mundiais de 2006 e 2008 que levaram ao aumento de populações expostas à fome.

\subsection{Sobre segurança alimentar}

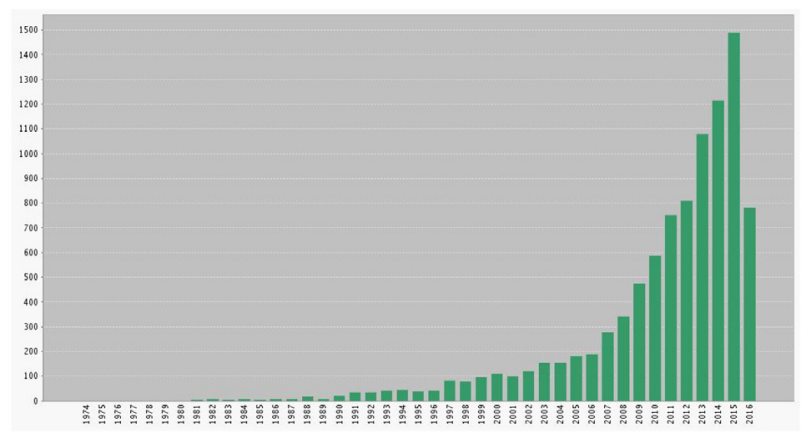

Fonte: Web of Science - artigos publicados sobre segurança alimentar. ${ }^{10}$

9 CASTRO, Josué de. Geografia da fome: o dilema brasileiro: pão ou aço. 10. ed. Rio de Janeiro: Antares, 1983.

10 Esta pesquisa foi feita no dia 04/08/16 no website da Web of 
Tomas Pogge identifica que "é notório o conhecimento atualmente que a humanidade já tem, há algum tempo, todos os meios econômicos, tecnológicos e administrativos para a erradicação completa da pobreza extrema em nosso planeta." ${ }^{11}$ Nesse sentido, a desigual distribuição dos alimentos e o precário acesso aos mesmos pela população é a primeira questão essencial para entender as causas da insegurança alimentar e as consequências da desnutrição, a qual, por sua vez, contribui para a promoção de doenças, tendo por si um grande impacto.

A insegurança alimentar diz respeito à falta de nutrientes e alimentos para a população permanecer "viva", estando diretamente ligada ao acesso diário a alimentos minimamente calóricos que são indispensáveis para que haja energia suficiente para a realização de atividades pelo indivíduo e do próprio funcionamento do organismo. ${ }^{12}$ Em 2000, de acordo com a Organização das Nações para Agricultura e Alimentação - FAO - por exemplo, um adulto, para ser considerado bem nutrido, deveria ingerir $2.500 \mathrm{kcal}$ por dia. Estas 2.500 kcal seriam, então, a linha divisória de identificação dos adultos que se alimentam além, aquém ou de acordo com o necessário ao bom funcionamento do organismo. ${ }^{13}$

A saúde vinda do latim 'salute', significa conservação da vida, vai depender da satisfação das necessidades biológicas básicas, o que lhe assegura as condições mínimas para o seu desenvolvimento, sendo atendidas as necessidades primárias para seu bem-estar. Nota-se que somente alimentar os famintos não alcança totalmente o objetivo para erradicar a fome.

Seja qual for o método de análise e monitoramento da insegurança alimentar, será preciso primeiro definir o que é considerado fome e em seguida quais procedimentos para estimar que a pessoa está enquadrada nesse conceito. O mais usado é o da FAO que define extrema forma de insegurança alimentar quando a energia inge-

Science tendo como parâmetro o termo "food security".

11 Tradução livre para o trecho "It is widely understood now that humanity has been in possession, for some time, of the economic, technological and administrative means for the complete eradication of severe poverty on our planet". POGGE, Tomas. The Hunger Games. Food ethics (2016) 1: 9. June 2016, Volume 1, Issue 1, pp 9-27

12 NUNES, Mérces da Silva. O direito fundamental à alimentação: e o princípio da segurança. Rio de Janeiro: Elseiver, 2008. 13 BEURLEN, Alexandra. Direito humano à alimentação adequada no Brasil. 3.ed. Curitiba: Juruá, 2008. rida pelos alimentos é insuficiente para suprir as necessidades mínimas de uma vida sedentária pelo período maior de um ano. ${ }^{14}$

Esse conceito tem algumas falhas, só considera a ingestão energética, porém seres humanos não conseguem viver apenas de energia precisam de nutrientes como proteínas, vitaminas, minerais e alguns micronutrientes para ser adequadamente nutrido e, em alguns casos, até para sobreviver. Principalmente três deficiências nutricionais relativas à pobreza têm causado milhares de mortes anualmente ${ }^{15}$ : a de vitamina A cuja deficiência aumenta substancialmente o número de mortes anuais de sarampo, diarréia e malária e também causa muita deficiência visual e cegueira; a falta de ferro que gera anemia generalizada em países pobres, provocando mortes em adultos, crianças e gestantes; a deficiência de zinco que, por sua vez, contribui substancialmente para as mortes por diarreia, pneumonia e malária em crianças menores de cinco anos; e a deficiência de iodo, a qual impede o desenvolvimento intelectual e físico.

Além disso, o conceito não leva em conta que centenas de milhões de pessoas em regiões pobres estão infectadas com parasitas que facilmente chegam a absorver mais de um terço dos nutrientes que são consumidos. Muitos, ainda sofrem de patologias que impedem a absorção adequada de nutrientes pelo intestino delgado. Para piorar, o conceito considera o mínimo de ingestão energética necessário para uma vida sedentária, mas nessas regiões esse estilo de vida não é realidade.

Há, portanto, o desafio de fazer com que a população consiga atingir e manter uma alimentação adequada, ou seja, acessar os alimentos em quantidade suficiente e que os mesmos sejam de qualidade. Também, de nada adianta assegurar o acesso ao alimento se o mesmo não for seguro, podendo trazer doenças ou complicações para a saúde. ${ }^{16}$ Existem requisitos mínimos sobre uma alimentação humana correta, no que tange a garantia de alimentos saudáveis, os quais devem ser: (I) seguros, isto é, livre de substâncias prejudiciais à saúde humana; (II)

14 FAO, WFP and IFAD (Food and Agriculture Organization of the United Nations, World Food Programme and International Fund for Agricultural Development). 2012. The state of food insecurity in the world 2012. Rome: FAO, 2012, p.50.

15 POGGE, Tomas. The Hunger Games. Food ethics (2016) 1: 9. June 2016, Volume 1, Issue 1, p. 11.

16 MÜLLER, Marcela. Direito fundamental à alimentação adequada no contexto das organizações internacionais. Curitba: Juruá, 2014, p.32-33. 
saudáveis, ou seja, capaz de gerar saúde ao ser humano, portanto nutritivo; e (III) culturalmente aceito.

Os sintomas da fome e suas causas se manifestam de maneiras diferentes em diferentes níveis da sociedade. É costume ver a fome mostrar-se em nível individual, mas a má distribuição dos alimentos existe em alguns níveis diferentes numa mesma sociedade. Existem cinco diferentes níveis, cuja separação metodológica serve apenas para uma melhor compreensão científica sobre o tema.

O primeiro é em nível internacional, no qual há uma má distribuição dos alimentos entre os países. $\mathrm{O}$ segundo é em nível nacional, sendo mal distribuídos os alimentos dentro de certas regiões ou áreas dentro de um país. O terceiro é em nível de área, em que se nota uma má distribuição de alimentos em bairros ou em determinadas localidades urbanas. A quarta é em nível local de bairro, no qual não são distribuídos de forma igualitária entre as residências e, por último, em nível de domicílios, onde os alimentos não são distribuídos corretamente entre os próprios membros do mesmo lar. ${ }^{17}$

\section{Histórico}

Em nível internacional, a preocupação e o conceito de segurança alimentar começaram a partir da $1^{\mathrm{a}}$ Guerra Mundial mostrando-se que um país poderia dominar o outro controlando seu fornecimento de alimentos, já que nem todos os países tinham uma capacidade suficiente de produzir seus próprios alimentos devido ao caos de guerra na Europa. ${ }^{18}$ Somente na década de 1940, que este conceito se referenciou em âmbito internacional, com a criação da FAO e de organismos internacionais para financiamentos, como o Banco Mundial (BM). ${ }^{19}$ Após a criação da $\mathrm{FAO}$, a primeira menção realizada a partir da questão alimentar se dá na VII Sessão da Conferência da FAO ocorrida em novembro de 1953, em que a assistência alimentar e a utilização de alimentos excedentes era vista como um artefato de segurança alimentar.

17 VALENTE, Luiz Schieck. Direito Humano à Alimentação: desafios e conquistas. São Paulo: Cortez, 2002.

18 NUNES, Mérces da Silva. O direito fundamental à alimentação: e o princípio da segurança. Rio de Janeiro: Elseiver, 2008, p. 58

19 VALENTE, Luiz Schieck. Direito Humano à Alimentação: desafios e conquistas. São Paulo: Cortez, 2002, p. 41
Esta preocupação estendeu-se até a metade dos anos setenta com a crise de escassez de alimentos, pois à capacidade de produção dos países estava diretamente ligada à segurança nacional. Nesta época, segurança alimentar não era considerado um direito do ser humano em ter acesso aos alimentos, mas sim uma política de armazenamento e oferta de alimentos visando à segurança do país, ou seja, a preocupação sempre esteve no alimento e não no ser humano, visto que quanto mais fosse produzido, mais aumentava sua segurança.

Decorrente das Grandes Guerras o alimento passou a ser arma poderosa de uma potência em relação a países mais pobres e incapazes de produzir seus próprios alimentos. Desta forma, os países tentavam atingir sua autossuficiência na produção dos alimentos, buscando eliminar ou reduzir embargos por motivações políticas ou militares. Como resultado, houve um aumento na produção de alimentos no início da década de 1980, mas a eliminação da fome e da desnutrição no mundo não ocorreu. Assim, mostrou-se indispensável cuidar do problema de oferta da capacidade de acesso aos alimentos, visto que esses problemas decorriam por serem muito mais problemas de demanda e distribuição do que propriamente de produção.

A FAO e a Organização Mundial da Saúde (OMS) apresentaram em 1983, um novo conceito de segurança alimentar, inserindo a "oferta adequada de alimentos, a sua estabilidade e a dos mercados de alimentação, bem como o acesso aos alimentos produzidos". Três anos depois, em 1986, o BM anunciou um conceito de segurança alimentar, qual seja, "o acesso por parte de todos, todo o tempo, de quantidade suficientes de alimentos para levar uma vida ativa e saudável"'.20

No contexto de uma economia globalizada, a
produção, a distribuição e o consumo de alimentos
(...) exigem que qualquer análise/ou abordagem
relativa à questão da Segurança Alimentar seja
realizada à luz do princípio da precaução que,
em prol da defesa e da proteção da coletividade,
apresenta-se como instrumento que deve ser
empregado na busca de soluções que permitam
agir com segurança em toda e qualquer situação
que envolva risco potencial que se trate de risco
conhecido ou desconhecido.

20 NUNES, Mérces da Silva. O direito fundamental à alimentação: e o princípio da segurança. Rio de Janeiro: Elseiver, 2008, p. 58-59.

21 NUNES, Mérces da Silva. O direito fundamental à alimentação: e o princípio da segurança. Rio de Janeiro: Elseiver, 2008 p.58. 
Ainda neste mesmo ano, a Cúpula Mundial de Alimentação, implantou a meta de erradicação da fome em todos os países e da redução de pessoas subnutridas até 2015, consolidando também um novo conceito de Segurança Alimentar. A Segurança Alimentar, nos níveis individual, familiar, nacional, regional e global, é alcançada quando todas as pessoas têm, a todo momento, acesso físico e econômico a alimentos inócuos (que não oferecem risco à saúde) e nutritivos para satisfazer suas necessidades dietéticas e preferências alimentares para uma vida ativa e saudável.

E em 1990, a FAO e a OMS acrescentaram ao conceito de segurança alimentar as noções de "alimento seguro ou não-contaminado, de qualidade nutricional e tecnológica, balanceamento da dieta e informação", visto que a segurança dos alimentos está diretamente relacionada ao cuidado, zelo e a atenção no ato de manter saudável a alimentação de outro ser humano.

Como visto anteriormente desde a década de 1980 até os dias atuais, há o problema de desigual distribuição de alimentos produzidos. Segundo Müller ${ }^{22}$, (existem três fatores que sustentam e confirmam a continuação do agravamento deste problema da alimentação da população mundial, sendo eles: (I) os problemas decorrentes do desperdício dos alimentos; (II) as controvérsias permanentes ao comércio internacional devido suas elevações dos preços bem como a quebra do funcionamento da produção nacional de alimentos; (III) e a desigualdade norte-sul sobre o acesso à alimentação, devido à escassez de recursos e de fornecimento dos alimentos para as pessoas.

Percebe-se, portanto que o conceito de Segurança Alimentar e Nutricional (SAN) está em constante estado de formulação, pois trata-se de tema global com uma pauta extensa e capilar, que se interliga as principais transformações ocorridas na sociedade moderna, como por exemplo, em relação a fome que se apresenta sob diversas circunstâncias ocasionadas por guerras, instabilidade política ou mesmo pelos fenômenos naturais, tais como mudanças climáticas que interferem na produção de alimentos. Ou mesmo, pela correlação do tema com a saúde humana e o consumo do alimento adequado e saudável.

22 MÜLLER, Marcela. Direito fundamental à alimentação adequada no contexto das organizações internacionais. Curitba: Juruá, 2014, p.42.

\section{No BRASIL}

Tal transformação conceitual e mesmo de compreensão se verifica também em relação a própria "segurança alimentar", que no Brasil tem estado em debate e modelagem há mais de vinte anos. Nesse sentido, o documento final da I Conferência Nacional de Alimentação e Nutrição, realizada em 1986 estabeleceu o conceito como sendo "a garantia, a todos, de condições de acesso a alimentos básicos de qualidade, em quantidade suficiente, de modo permanente e sem comprometer o acesso a outras necessidades básicas, com base em práticas alimentares que possibilitem a saudável reprodução do organismo humano, contribuindo, assim, para uma existência digna."23

No campo legal brasileiro, o advento da Lei $\mathrm{n}^{\circ}$ 11.346, de 15 de setembro de 2006 cria o Sistema Nacional de Segurança Alimentar e Nutricional - SISAN com vistas a assegurar o direito humano à alimentação adequada. O marco legal

estabelece as definições, princípios, diretrizes, objetivos e composição do Sistema Nacional de Segurança Alimentar e Nutricional - SISAN, por meio do qual o poder público, com a participação da sociedade civil organizada, formulará e implementará políticas, planos, programas e ações com vistas em assegurar o direito humano à alimentação adequada. ${ }^{24}$

A contextualização elaborada, remete a algumas considerações. A primeira delas está relacionada a conceituação de segurança alimentar global diante de uma perspectiva contemporânea que ainda carece de melhor compreensão em face de seu alargado escopo e, que possa ser internalizada e compreendida no Brasil a partir de uma visão sistêmica que observe as variáveis cultural, social, ambiental, econômica, saúde pública etc) e que considere conjunturas regionais e locais.

Outro aspecto está no campo jurídico-legal, que carece ainda de uma ampliação e aperfeiçoamento da estrutura legal, bem como de aprofundamento doutrinário, tendo em vista o principal marco legal ter apenas uma década de vigência. Isso significa dizer, que o "direito à alimentação" previsto na carta magna coloca em perspectiva, especialmente para o Poder Público novos

23 LEÃO, Marília (Org.). O Direito Humano à Alimentação Adequada e o Sistema nacional de Segurança Alimentar e Nutricional. Brasília: ABRANDH, 2013, p. 15.

24 Lei no $11.346 / 2006$, art. $1^{\circ}$. 
deveres até então não percebidos e devidos em políticas públicas.

Por fim, a segurança alimentar e nutricional trata-se de temática nova, porém estratégica para a sociedade contemporânea e, aguarda-se que ganhe mais espaço na agenda do poder público, setor empresarial, academia e sociedade civil com o objetivo macro de garantir às presentes e futuras gerações uma satisfatória qualidade de vida a partir de uma alimentação saudável e adequada.

Estão em trâmite no Congresso Nacional brasileiro três projetos de lei. O primeiro dispõe sobre a redução do desperdício de alimentos, estabelecendo que

$$
\begin{aligned}
& \text { os estabelecimentos dedicados a comercialização } \\
& \text { ou manipulação de alimentos firmarão contratos de } \\
& \text { doação a organizações de natureza social dedicadas } \\
& \text { à coleta e distribuição de alimentos e refeições, } \\
& \text { ou de doação ou venda a empresas dedicadas à } \\
& \text { produção de ração animal e à compostagem. Isenta } \\
& \text { o doador de responsabilidade por dano ocasionado } \\
& \text { pelo consumo do bem, desde que não caracterize } \\
& \text { dolo e negligência. }
\end{aligned}
$$

O segundo estabelece a Política Nacional de Combate ao Desperdício de Alimentos, com o objetivo de "aumentar o aproveitamento dos gêneros alimentícios disponíveis para consumo humano em território nacional", mitigando, assim o desperdício alimentar com o "uso dos alimentos impróprios para o consumo humano em atividades de reciclagem e de alimentação de animais" 26 . O terceiro projeto de lei, por sua vez, estabelece as diretrizes para a "Política Nacional de Erradicação da Fome e de Promoção da Função Social dos Alimentos - PEFSA, fundamentada em uma sociedade fraterna, justa e solidária". ${ }^{27}$

Assim, se no passado a agenda da SAN estava voltada a garantir a capacidade de cada país produzir sua alimentação, bem como a insegurança alimentar decorrida da produção insuficiente de alimentos, sobretudo, entre os países pobres, isso tem sido ampliado. A importância da SAN, na atualidade e seu conceito tem sido objeto de permanente construção e evolução diante das transformações vivenciadas pela sociedade e tem abarcado temas relacionados à saúde humana, especialmente o combate a obesidade e sobrepeso, a saudabilidade e qualidade nutricional dos alimentos, bem como a ampliação das condições de oferta acessível de alimentos.

25 PROJETO DE LEI DO SENADO nº 672, de 2015

26 PROJETO DE LEI DO SENADO n 675, de 2015

27 PL 6867/2013 - CÂMARA DOS DEPUTADOS
Isso por meio do incremento da produção, em especial na agricultura tradicional, familiar, urbana, periurbana, no processamento, na industrialização, na comercialização e no abastecimento, que demandam ações intersetoriais que devem orientar governos e suas políticas públicas.

\section{Desperdício}

De acordo com a FAO, o volume de desperdício de alimentos em todos os países, tem sua diversidade. Em um lado da balança tem-se o desperdício em âmbito internacional, chegando a 1,3 bilhão de toneladas por ano, suficiente para alimentar mais que o dobro das pessoas que hoje sofrem da falta de alimentos; e do outro lado, a questão em que por volta de 870 milhões de pessoas ainda passam fome. ${ }^{28}$

A avaliação ambiental de todos os produtos é baseada em uma abordagem de ciclo de vida que engloba todo o "ciclo alimentar", incluindo a produção agrícola, processamento pós-colheita e armazenamento, distribuição, consumo ou a sua eliminação. Algumas dessas perdas se dão em cada fase da cadeia de fornecimento dos alimentos, principalmente em países em desenvolvimento, como à falta de armazéns adequados, de estradas e de sistemas de refrigeração. Há também problemas de perdas em países desenvolvidos, no qual desperdiçam mais comida nas etapas após o fornecimento aos varejistas, que encomendam, servem e exibem os produtos, e seguindo esta cadeia até os consumidores finais que, muitas vezes, ignoram os restos de alimentos ainda na geladeira, descartando alimentos ainda válidos ou, em razão do tempo, podres.

Esse mesmo estudo realizado pela $\mathrm{FAO}^{29}$, não calculou somente os volumes de alimentos desperdiçados, calculou também os seus impactos ambientais, já que esse desperdício, além de causar enormes problemas sociais e econômicos, traz impactos sobre recursos na-

28 FAO. Organização das Nações Unidas para a Alimentação e a Agricultura. $\mathbf{O}$ desperdício alimentar tem consequências ao nível do clima, da água, da terra e da biodiversidade - novo estudo da FAO. Roma, 2013. Disponível em: <http://www.fao.org/ news/story/pt/item/204029/icode/>. Acesso em: 05 jun. 2016.

29 FAO. Organização das Nações Unidas para a Alimentação e a Agricultura. $\mathbf{O}$ desperdício alimentar tem consequências ao nível do clima, da água, da terra e da biodiversidade - novo estudo da FAO. Roma, 2013. 
turais disponíveis. Assim, quanto maior for a quantidade de alimentos perdidos ou desperdiçado ao longo da cadeia de abastecimento, maior será o custo ambiental. Os impactos ambientais são avaliados em quatro componentes: clima, água, solo e biodiversidade.

Todo este manancial de recursos naturais disponíveis para a produção de alimentos, com o tempo vai contribuindo para sua escassez, pois alimentos produzidos que não iram ser consumidos, além de estarem desfazendo-se do próprio alimento, perdem os recursos naturais que a natureza levou milhares de anos para disponibilizar $^{30}$

\section{Comércio internacional e meio ambiente}

O próximo ponto sobre a desigual distribuição, aborda o comércio internacional quanto às causas da fragilização da economia local. A estabilidade de uma economia local, decorre dos pequenos agricultores, responsáveis pela produção de alimentos primários que virão a ser comercializados e conseguem manter sua vida e sua família na área rural, garantindo também a qualidade sobre os alimentos. O problema surge quando há uma abertura de mercado para multinacionais, pois elas acabam prejudicando o pequeno agricultor, uma vez que os investimentos na produção são estrangeiros e os lucros tendem a não permanecer no local de produção.

O mercado de alimentos global é dominado por pequeno número de empresas que dominam a oferta de mercado, pois há poucos vendedores para muitos compradores. Esse é um dos principais obstáculos do direito social fundamental à alimentação adequada. Isso porque somente as maiores empresas possuem e permanecem com o controle da produção, da comercialização de sementes e, posteriormente, do alimento com o seu devido preço junto ao mercado de commodities. ${ }^{31}$

Dessa maneira, por não serem de seu interesse, estes oligopólios não visam às pequenas produções de alimentos, que são os principais responsáveis pela segurança alimentar, especialmente para as pessoas mais desprovidas, pela sua dificuldade ao acesso ao que é

30 MÜLLER, Marcela. Direito fundamental à alimentação adequada no contexto das organizações internacionais. Curitba: Juruá, 2014, p.43.

31 ZIEGLER, Jean. Destruição em massa: Geopolítica da fome. São Paulo: Cortez, 2013. ofertado pelas grandes indústrias. E, por fim, a desigualdade norte-sul, em que os países do Norte apresentam melhores condições de acesso e qualidade dos alimentos do que comparados aos do Sul. Neste sentido, Moeller constata:

Organizações como empresas multinacionais, ou pelo menos os partidos políticos influenciados por suas doações, parecem estar ganhando cada vez maior controle sobre os governos em todos os níveis, do local ao global, e estão tomando o poder das mãos dos. ${ }^{32}$

A problemática da erradicação da fome está associada à intensificação do processo de internacionalização das empresas transnacionais (ETNs) ligadas ao setor agrícola e apresenta um complicador para se chegar a um consenso mínimo quanto às causas estruturais da fome e as formas de seu combate: seu objetivo primário não é a erradicação da fome, mas o acúmulo de capital, que segundo Foster:

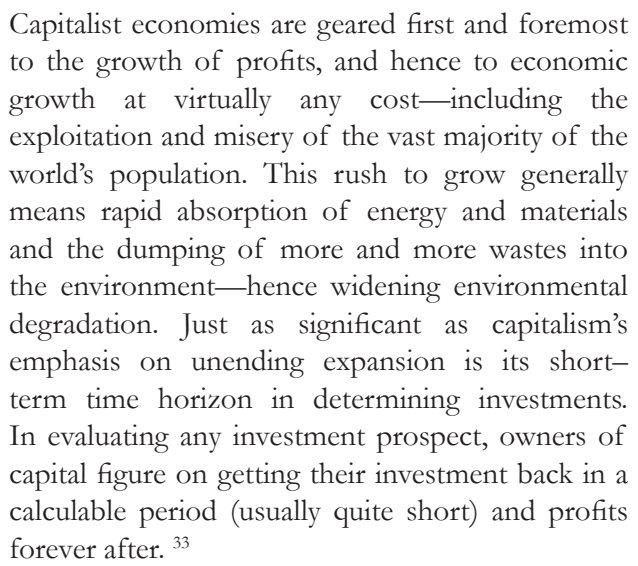

Embora as ETNs não tenham a missão de combater a fome e a prática adotada por elas da monocultura está associada direta ou indiretamente aos maiores desafios ambientais vivenciados neste século, elas apresentam uma concentração de poder na governança do sistema alimentar internacional sem precedentes. Conforme Clapp e Fuchs:

Private, corporate actors have taken on a significant role in the global food system, not only as economic actors responsible for much of the world's food

32 Tradução livre para: "Organizations such as multinational corporations_-or at least the political parties influenced by their donations - seem to be gaining increasing control of the governments at all levels, from local to global, and to be taking power out of the hands of individual citizens" MOELLER, H.-G. Luhmann Explained: From Souls to Systems. Chicago: Open Court, 2006. 33 FOSTER, J. B. Ecology Against Capitalism. Monthly Review. Recuperado agosto 4, 2016, de http://monthlyreview. org/2001/10/01/ecology-against-capitalism/, 2001, outubro 1. 
production, processing, and retailing, but also as political actors in global mechanisms to govern the food system. ${ }^{34}$

Seu crescimento econômico e político está tornado principalmente os países em desenvolvimento grandes exportadores de commodities e grandes compradores de produtos industrializados. O relatório The ECT Century - Erosion, Technology and Corporate Concentrationin the $21^{\text {st }}$ Century apresenta os vários estágios e graus em que as ETNs interferem na cadeia produtiva agrícola:

- The top 10 seed companies control nearly 50 percent of the US $\$ 21$ billion annual global commercial seed market and nearly all of the genetically engineered seed market.

- The top 10 pesticide companies control 84 percent of the US $\$ 30$ billion annual global pesticide market.

- The top 10 food retailers control 24 percent of the estimated US $\$ 3.5$ trillion global food market.

- The top 10 food and beverage processing companies control 24 percent of the estimated US $\$ 1.25$ trillion global market for packaged foods. ${ }^{35}$

Segundo Clapp e Fuchs, $[\ldots]$ there is a growing critique of the effects that corporate concentration in a globalized food system is having on food security, small-farmer livelihoods, environmental quality, food safety, and consumer sovereignty ${ }^{36}$, o que ocorre em razão de sua visão de curto-prazo no que diz respeito aos investimentos e a forma de sua recuperação, utilizando as monoculturas, pesticidas e GMOs que comprometem seriamente a biodiversidade, aumentam a vulnerabilidade dos países às crises internacionais de commodities e o modus vivendi de milhões de pessoas que vivem no campo.

Para tanto, o exercício de seu poder econômico e político é exercido nas dimensões instrumental e estrutural.

34 CLAPP, J.; COHEN, M. J. Global Food Crisis: Governance Challenges and Opportunities. Waterloo, Ont.: Wilfrid Laurier University Press, 2009.

35 In http://www.etcgroup.org/sites/www.etcgroup.org/files/ publication/281/01/other_etccentury.pdf. Acesso em: 04/08/16.

36 CLAPP, J.; COHEN, M. J. Global Food Crisis: Governance Challenges and Opportunities. Waterloo, Ont.: Wilfrid Laurier University Press, 2009.
$\mathrm{Na}$ dimensão instrumental elas interferem na mais óbvia forma que é o financiamento de campanhas eleitorais, enquanto na estrutural elas influenciam o processo político a partir de um sistema de recompensas e punições dependendo do comportamento dos Estados (p.ex. aumento ou redução de investimentos) e a implementação de um sistema privado de regulação que força os Estados a legitimar tais regimes privados via instituições internacionais (p.ex. ISO 14000). Neste sentido, o agronegócio:

[...] é uma forma de territorialização do capital no campo, que se concretiza no domínio do mercado de insumos, das técnicas e tecnologias da produção, dos sistemas de financiamento, das indústrias de beneficiamento, dos sistemas de transporte e das redes de comercialização. Além disso, esses grupos exercem poder e influência sobre órgãos internacionais como a Organização Mundial do Comércio (OMC), que define regras para o comércio de produtos agrícolas no mundo. ${ }^{37}$

Chegamos assim na encruzilhada em que a necessidade de diminuir a exposição de pessoas aos efeitos negativos da fome pelo aumento da segurança alimentar que é feito pelo sistema alimentar atual controlado pelas ETNs encontra outra dimensão da segurança, a ecológica. Ao relatar a experiência da revolução verde na região de Punjab, Índia, Shiva ${ }^{38}$ coloca:

'Green Revolution' is the name given to this science based transformation of Third World agriculture, and the Indian Punjab was its most celebrated success. Paradoxically, after two decades of the Green Revolution, Punjab is neither a land of prosperity, nor peace. It is a region riddled with discontent and violence. Instead of abundance, Punjab has been left with diseased soils, pestinfested crops, waterlogged deserts and indebted and discontented farmers. Instead of peace, Punjab has inherited conflict and violence. At least 15,000 people have lost their lives in the last six years. 598 people were killed in violent conflict in 20 The Violence of the Green Revolution Punjab during 1986. In 1987 the number was 1544. In 1988, it had escalated to 3,000. And 1989 shows no sign of peace in Punjab. The tragedy of Punjab - of the thousands of innocent victims of violence over the past five years - has commonly been presented as an outcome of ethnic and communal conflict between two religious groups.

Assim, temos um discurso que permeia as instituições internacionais que a segurança alimentar passa

37 SOGLIO, F. D.; KUBO, R. R. Agricultura e Sustentabilidade. PLAGEDER, 2009. In http://www.ufrgs.br/cursopgdr/ downloadsSerie/derad008.pdf. Acesso em: 29/10/16.

38 SHIVA, V. Monoculturas Da Mente. Perspectivas Da Biodiversidade E Biotecnologia. São Paulo: Gaia, 2003, p.19. 
pelo aumento da produção agrícola que a revolução verde proporciona, incluindo o uso de novas tecnologias para superar as limitações impostas pelo meio ambiente, que, no entanto, gera uma maior insegurança tendo em vista o elevado grau de vulnerabilidade introduzida no sistema alimentar, a destruição da biodiversidade, os efeitos adversos no meio ambiente pela introdução de elementos poluidores, o êxodo rural e o aumento da violência no campo, dentre outros. Todos estes fatores contribuem para uma situação de dilema de segurança, em que a tentativa de aumentar a segurança apresenta o efeito oposto, gerando uma espiral de insegurança que torna cada vez mais instável o sistema internacional. Segundo Tang ${ }^{39}$, o dilema de segurança apresenta seis proposições que configuram sua presença:
(1) its ultimate source is fear, which is derived from the "universal sin of humanity";0 (2) it requires uncertainty over others' intentions; (3) it is unintentional in origin; (4) it produces tragic results; (5) it can be exacerbated by psychological factors; and (6) it is the fundamental cause of all human conflicts.

Ampliar a segurança alimentar utilizando o modelo de produção agrícola dominante apresenta falhas graves e gera mais insegurança. O IAASTD no Food Security in a Volatile World apresenta como uma de suas recomendações de natureza urgente para lidar com o tema de segurança alimentar o seguinte:

\begin{abstract}
Promote the diversification of production systems through inclusion of locally important species/ crops to develop a wide range of marketable natural products that can generate income for the rural and urban poor in the tropics and provide ecosystem services, such as soil and water conservation. ${ }^{41}$
\end{abstract}

\section{Direitos humanos}

O direito humano à alimentação foi anunciado enquanto um direito básico do homem na Declaração Universal dos Direitos Humanos (DUDH) de 1948, criando-se uma perspectiva legal e institucional so-

39 TANG, S. The Security Dilemma: A Conceptual Analysis. Security Studies, v. 18, n. 3, p. 587-623. doi: 10.1080/09636410903133050, 2009.

40 Segundo o próprio Tang (2008), Robert Jervis e John Herz apontam ser a fonte primária do dilema de segurança a estrutura anárquica do sistema internacional, o que concordamos.

41 In http://www.unep.org/dewa/agassessment/docs/10505_ FoodSecurity.pdf. Acesso em:05/08/16. bre o tema. ${ }^{42}$ No art. 25 da DUDH consta que "toda pessoa tem direito a um nível de vida suficiente para lhe assegurar a si e à sua família a saúde e o bem-estar, principalmente quanto à alimentação (...)", marcando formalmente o surgimento de uma obrigação as nações perante o ser humano. ${ }^{43}$

Em 1966 a ONU estabeleceu o Pacto Internacional dos Direitos Econômicos, Sociais e Culturais (PIDESC), o qual reconhecem o direito básico sobre uma alimentação adequada. ${ }^{44}$ Segundo Valente ${ }^{45}$, sem este Pacto não poder-se-ia discutir os outros direitos, uma vez que sem uma alimentação adequada, referindo-se a quantidade e qualidade suficientes, não há o direito à vida.

Aliás, o direito à vida é assegurado pelo Pacto Internacional de Direitos Civis e Políticos (PIDCP), em seu artigo $\mathrm{n}^{\circ} 6$, o qual estabelece que " $\mathrm{O}$ direito à vida é inerente à pessoa humana. Este direito deverá ser protegido pela lei. Ninguém poderá ser arbitrariamente privado de sua vida. "Somado a esse o artigo $\mathrm{n}^{\circ} 11$ do PIDESC declara que qualquer pessoa, independentemente de onde estiver em hipótese alguma poderá sentir fome, ou seja, todo ser humano tem o direito de não sentir fome, seguindo o direito de uma alimentação adequada e saudável - ambos ratificados pelo Brasil em 1992.

A FAO, nesse sentido, foi edificada para combater e eliminar a fome mundial, conforme ${ }^{46}$ ressalta:

Os Estados que adotam (aceitam) esta Constituição,
decidimos a promover o bem-estar geral,
intensificando, por sua parte, a ação individual e
coletiva com os fins de: elevar os níveis de nutrição
e de vida (...) e contribuir, assim (...) a libertar a
humanidade da fome; $[. . .]^{47}$

Precisa-se analisar que se necessita deixar de lado questões como fronteira, e questões econômicas para que as pessoas consigam comprar seus alimentos, ter condições de acesso ou possuir meios para produzir.

42 PIOVESAN, Flávia. Direitos humanos e o direito constitucional internacional. $13^{\circ}$ ed, p.6. São Paulo: Saraiva, 2007.

43 MÜLLER, Marcela. Direito fundamental à alimentação adequada no contexto das organizações internacionais. p.56. Curitba: Juruá, 2014.

44 Ibidem p.56.

45 VALENTE, Luiz Schieck. Direito Humano à Alimentação: desafios e conquistas. p.37. São Paulo: Cortez, 2002.

46 NUNES, Mérces da Silva. $\mathbf{O}$ direito fundamental à alimentação: e o princípio da segurança. p.52. Rio de Janeiro: Elseiver, 2008.

47 Ibidem FAO apud NUNES, 2008, p.52. 
Afinal, qualquer pessoa como sujeito de direito, tem o direito de contribuir para melhorar suas condições de existência e não somente esperar alguma atitude do Estado prover uma resposta aos problemas enfrentados pela população, como é a fome e a desnutrição. Percebe-se logo, a função fundamental do direito do livre acesso, tanto físico como econômico, à vida digna, o que inclui o alimento. ${ }^{48}$

Acerca disso, estabeleceu o Pacto Mundial de Segurança Alimentar (PMSA), de 1985, em seu art. $3^{\circ}$ :

\begin{abstract}
A realização da segurança alimentar mundial deve ser um objetivo integrante dos planos econômicos e sociais. As medidas devem ter por finalidade a consecução de três objetivos concretos: produzir um volume apropriado de alimentos, aumentar a estabilidade da oferta alimentar e assegurar o acesso aos alimentos às pessoas que deles necessitam. ${ }^{49}$
\end{abstract}

Ainda no contexto internacional, no ano de 2005, a FAO editou um documento denominado 'Diretrizes Voluntárias para Implementação do Direito Humano à Alimentação Adequada', direcionado ao contexto da segurança alimentar. Nele buscou-se firmar um conjunto de diretrizes, no qual os Estados executam e praticam o direito humano à alimentação em todos os níveis, repassando orientações para que os países possam implementar as políticas públicas que irão proporcionar e prover uma mínima qualidade de atendimento ao direito à alimentação. ${ }^{50}$

Em âmbito brasileiro, "[o] acesso à alimentação é um direito humano em si mesmo, na medida que a alimentação constitui-se no próprio direito à vida. Negar esse direito é, antes de mais nada, negar a primeira condição para a cidadania, que é a própria vida" ${ }^{\circ 1}$, mas somente em 2010 o direito fundamental à alimentação foi incluído à Constituição de 1988, no art. 6 por meio da Emenda Constitucional $n^{\circ}$ 64, passando a ser um direito social fundamental. ${ }^{52}$

48 MÜLLER, Marcela. Direito fundamental à alimentação adequada no contexto das organizações internacionais. p.57. Curitba: Juruá, 2014.

49 NUNES, Mérces da Silva. O direito fundamental à alimentação: e o princípio da segurança. PMSA apud NUNES, 2008, p. 54. Rio de Janeiro: Elseiver, 2008.

50 MÜLLER, Marcela. Direito fundamental à alimentação adequada no contexto das organizações internacionais. p.57-58. Curitba: Juruá, 2014.

51 MRE. MINISTÉRIO DAS RELAÇÕES EXTERIORES. Banco Mundial. [s/d]. Disponível em: <http://www.itamaraty. gov.br/pt-BR/politica-externa/diplomacia-economica-comercial-efinanceira/120-banco-mundial>. Acesso em: 01 jun. 2016.

52 Ibidem p.58.
As primeiras menções sobre o conceito de segurança alimentar no Brasil aparecem somente em 1985 no Ministério da Agricultura (MA) com o começo de uma proposta de Política Nacional de Segurança Alimentar (PNSA). Esta proposta visava responder todas as dificuldades e ausências no que correspondia compreender e alcançar autossuficiência na produção de alimentos e abrangeu a criação de um Conselho Nacional de Segurança Alimentar. ${ }^{53}$

Em 1986, com a I Conferência Nacional de Alimentação e Nutrição, o Brasil adotou um novo conceito de segurança alimentar, consolidando-se em 1994, com a I Conferência Nacional de Segurança Alimentar. ${ }^{54}$ No conceito e concepção brasileira:

\begin{abstract}
Segurança Alimentar e Nutricional consiste em garantir a todos as condições de acesso a alimentos básicos, seguros e de qualidade, em quantidade suficiente, de modo permanente e sem comprometer $\mathrm{o}$ acesso a outras necessidades essenciais, com base em práticas alimentares saudáveis, contribuindo assim para uma existência digna em um contexto de desenvolvimento integral da pessoa humana. ${ }^{55}$
\end{abstract}

O direito fundamental à alimentação encontra-se claro e assegurado na Constituição Federal (CF) de 1988, em diversas prescrições e artigos de lei. Inicialmente, ele está contido no próprio art. $1^{\circ}$ da $\mathrm{CF}$, quando o inciso III traz a dignidade humana como seu fundamento. Afinal a dignidade da pessoa humana só é garantida quando atendida suas condições existenciais mínimas e indispensáveis, como acesso à moradia, alimentação, saúde, educação, entre outras.

Além disso, constitui um dos objetivos da nação a própria erradicação da pobreza e da marginalização, reduzindo as desigualdades como prevê o art. $3^{\circ}$, inciso III da CF. Logo, deve o Estado adotar providências positivas e efetivas voltadas ao combate à pobreza e à marginalização, o que inclui a garantia do alimento.

Conforme o art. 4 o Brasil rege-se as suas relações internacionais pelos princípios como o da prevalência dos direitos humanos previsto no inciso II da CF. Sobre os direitos e garantias fundamentais segue no capítulo II da Constituição o art. $6^{\circ}$ aborda que "São direitos sociais a educação, saúde, o trabalho, a moradia, o lazer,

53 VALENTE, Luiz Schieck. Direito Humano à Alimentação: desafios e conquistas. p.45. São Paulo: Cortez, 2002.

54 Ibidem p.45.

55 NUNES, Mérces da Silva. $\mathbf{O}$ direito fundamental à alimentação: e o princípio da segurança. CNAN apud NUNES, 2008, p. 60. Rio de Janeiro: Elseiver, 2008. 
a segurança (...)". Já o art. $7^{\circ}$ continua a abordar os direitos dos trabalhadores urbanos e rurais, no qual visem à melhoria de sua condição social, para isso, o Estado deve garantir o salário mínimo que seja capaz de atender todas ás necessidades do ser humano e de sua família conforme o inciso IV.

É de competência da União também, previsto no art. $23^{\circ}$ combater os efeitos da pobreza, mas deve buscar-se eliminar todas as suas causas, trabalhando de forma efetiva para que exista uma melhoria na qualidade de vida das pessoas e da população.

O Sistema Nacional de Segurança Alimentar (SISAN), criado em 15 de setembro de 2006, pela Lei $\mathrm{n}^{\circ}$ 11.346 - Lei Orgânica de Segurança Alimentar e Nutricional (LOSAN), com o principal objetivo de garantir o direito à alimentação adequada, ${ }^{56}$

[o] SISAN tem por objetivos formular e implementar políticas e planos de segurança alimentar e nutricional, estimular a integração dos esforços entre governo e sociedade civil, bem como promover o acompanhamento, o monitoramento e a avaliação da segurança alimentar e nutricional no país. ${ }^{57}$

Além disso, conforme o art. $2^{\circ}$ da referida lei:

\begin{abstract}
A alimentação adequada é direito fundamental do ser humano, inerente à dignidade da pessoa humana e indispensável à realização dos direitos consagrados na Constituição Federal, devendo o poder público adotar as políticas e ações que se façam necessárias para promover e garantir a segurança alimentar e nutricional da população. ${ }^{58}$
\end{abstract}

Sob a compreensão dos citados artigos de lei até o momento, nota-se que o direito à alimentação, além de estar na essência da estruturação de direitos básicos ao homem, originário de documentos internacionais, foi sancionado e reconhecido por ser indispensável e são protegidos tanto na Constituição como em normas infraconstitucionais. Para além da realização dos direitos fundamentais ligados à segurança alimentar, que como explicado anteriormente, depende da adoção de políticas públicas que alterem o modelo existente no sentido

56 MÜLLER, Marcela. Direito fundamental à alimentação adequada no contexto das organizações internacionais. p.95. Curitba: Juruá, 2014.

57 SISAN. Sistema Nacional de Segurança Alimentar e Nutricional. Sistema Nacional de Segurança Alimentar e Nutricional. Brasília, 2003. Disponível em: < http://www4.planalto.gov.br/consea/acesso-a-informacao/institucional/conceitos/sistema-nacional-de-seguranca-alimentar-e-nutricional>. Acesso em: 07 jun. 2016. 58 Ibidem de empoderar seus destinatários, se torna necessário também o exame das implicações do atual modelo alimentar em outros direitos fundamentais. ${ }^{59}$

Conforme ficou consignado anteriormente, o modelo do sistema internacional de alimentos está ancorado na participação sem precedentes nas ETNs, que controlam senão toda, boa parte da cadeia produtiva alimentar. Assim, a construção do discurso baseado na falsa premissa de que é necessário o aumento da produção de alimentos para erradicar a fome tem as ETNs como os agentes securitizadores do tema alimentação, cuja audiência encontra boa receptividade por parte dos Estados.

A securitização é um ato de discurso ou linguagem que transforma um fenômeno que é originariamente pertencente a política para a área de segurança (etiquetar o assunto como sendo de segurança). Assim, a securitização da alimentação a partir das narrativas sobre a fome apresentou um objeto que se identificou com uma ameaça existencial potencial nas dimensões internacional e nacional. As narrativas encontram eco em uma audiência que se dispôs securitizar, o que justificou a adoção de medidas emergenciais ou recursos extraordinários para enfrentar a ameaça.

Securitizar é o que Buzan et $\mathrm{al}^{60}$ chamou de política do pânico, em que determinados assuntos de políticas públicas tornam-se confidenciais justificando-se como Raison d'État; direitos e garantias são suprimidas e poderes adicionais são conferidos aos agentes públicos, tudo em nome de um "bem maior". Trata-se de um processo intersubjetivo e prática auto-referida entre ator securitizador, objeto de securitização e audiência.

Além da problemática de supressão de direitos fundamentais em razão da securitização, o modelo atual baseado na monocultura possui um grande potencial de agressão ao meio ambiente (uso crescente de pesticidas, utilização indiscriminada de GMOs e grande consumo de energia para o transporte das commodities do local de produção para os centros de consumo), pois tende a destruir a biodiversidade e por em risco a soberania alimentar local, esclarece Shaw. ${ }^{61}$

59 AMIN, S.; PATEL, R.; SCHUTTER, O. D.; STEDILE, J. P. Food Movements Unite!: Strategies to Transform Our Food System (E. Holt-Gimenez, Org.). Oakland, CA: Food First Books, 2011.

60 BUZAN, B.; WVER, O.; WILDE, J. D. Security: A New Framework for Analysis. Boulder, Colo: Lynne Rienner Pub, 1997. 61 SHAW, D. World Food Security: A History since 1945. 2007 
Com isso, sob a pretensão de aumento da segurança alimentar o que temos é um aumento na insegurança alimentar pois todo sistema se torna ainda mais vulnerável às crises e gera ainda a insegurança ambiental e societal. ${ }^{62}$

\section{Governança global}

O problema da insegurança alimentar tem natureza complexa o que dificulta a eficácia de medidas resolutivas contundentes e sancionatórias. $\mathrm{O}$ avanço nessa área vai, portanto depender da articulação de interesses muitas vezes opostos, inclusive. Diversos canais formais e informais precisam ser construídos para conectar sociedade, iniciativa privada e governos nos âmbitos locais, regionais, federais e global. Canais esses que são fundamentais para a organização da sociedade e tempos de interdependência complexa ${ }^{63}$ entre estados, entre governos e nas relações internacionais de forma mais abrangente.

Conforme a complexidade dos atores e dos temas da política global aumentam, a possibilidade do uso da força, diminui e, com isso, enfraquecem as barreiras divisórias entre local, regional, nacional estrangeiro, assim como entre o publico e o privado. A formação da agenda política, econômica, social e cultural se torna sutil, difusa e muitas vezes altamente especializada e específica para situações ad hoc ou circunstanciais. E os diversos atores surtem efeitos recíprocos, muitas vezes atuando em um tabuleiro objetivando ganhos em outros.

Para tanto, pressupõe um processo continuo de acomodação de interesses conflitantes em busca de ações cooperativas, no âmbito, tanto das instituições formais e dos acordos coercitivos, como em regimes montados para buscar compromissos voluntários e via acordos informais. Assim, as instituições são complementadas por regimes de política internacional, formados a partir de um conjunto de explícitos e implícitos princípios, normas, regras e procedimentos de tomada de decisão

edition ed. Basingstoke England; New York: Palgrave Macmillan, 2007, p. 15.

62 VILLA, R. D. Multidimensional global security. Lua Nova: Revista de Cultura e Política, , n. 46, p. 99-118. doi: 10.1590/ S0102-64451999000100005, 1999.

63 KEOHANE, Robert O.; NYE, Joseph. Power and Interdependence: World Politics in Transition. Nova York: Longman, 2001. capaz de proporcionar a convergência das expectativas dos atores em uma determinada temática.

Os objetivos do desenvolvimento sustentável têm essa finalidade de proporcionar a convergência de esforços em determinadas temáticas. Mas precisam que sejam muito bem feitas as métricas de acompanhamento do cumprimento dessas metas e que haja ferramentas eficientes de revisão para adequar o acordado com os modelos de implementação e de acompanhamento disponíveis num determinado momento.

Um dos problemas do sistema é que estatísticas podem ser manipuladas sem necessariamente deixar de mostrar a realidade. São os próprios países e seus governos locais que fornecem dados sobre o cumprimento ou não das metas. Além disso, a questão da fome propriamente dita tem um interesse político crucial para os Estados e portanto as organizações internacionais multilaterais responsáveis pelo acompanhamento das metas, como a FAO e o Banco Mundial, podem ser vulneráveis à pressão política. Afinal, os Estados membros têm a liberdade de apontar ou substituir a qualquer momento os seus representantes nessas organizações e são os Estados que contribuem com o orçamento das organizações internacionais.

O Portal ODM ${ }^{64}$ no âmbito do Brasil, é um exemplo de ferramenta criada para acompanhar o cumprimento das metas, apresentando dados relacionados a elas em relação a cada um dos 5.564 municípios brasileiros. A iniciativa é resultado de uma parceria entre o Observatório de Indicadores de Sustentabilidade, o programa SESI do Paraná, o Sistema FIEP e o Instituto de Promoção do Desenvolvimento, sob a coordenação do Programa das Nações Unidas para o Desenvolvimento e apoio do Fundo das Nações Unidas para a Infância, o Movimento Nós Podemos Paraná, o Núcleo de Apoio a Políticas Públicas, o Ministério do Planejamento e a Secretaria Geral da Presidência da República.

A finalidade desse portal é permitir que a Administração, empresas e também a sociedade possam acompanhar a prática de seus municípios, envolvendo o atores em âmbito local no processo de implementação de políticas públicas. Todavia, ainda que as informações, estejam previstas para serem atualizadas em tempo real, nem sempre os dados oficiais estão disponíveis, apesar

64 FIEP. Portal ODM. Disponível em < http://www.portalodm. com.br > Acesso em 10 de outubro de 2016. 
da vigente Lei de Acesso a Informação.

A principal função do portal é traduzir a linguagem técnica dos dados contidos em documentos oficiais para o público em geral. As informações podem ser consultadas em relatórios dinâmicos que incluem números, gráficos e comparativos com as metas, pois as informações brasileiras são integradas ao sistema de informação da ONU, chamado DevInfo ${ }^{65}$. Por meio desse programa é possível gerar relatórios específicos, personalizados, cruzando os diferentes indicadores e comparando esses dados entre cidades, estados e regiões.

O DevInfo é um sistema de gerenciamento de dados relativos ao desenvolvimento humano. É uma ferramenta tecnológica para estocar, organizar e apresentar informações de uma maneira uniforme que facilite o compartilhamento. Esse software agrega indicadores previstos nos ODS e também outros definidos pelos usuários. Segue os padrões internacionais de estatística, funciona instalado e também online para facilitar o acesso público e disseminado aos seus registros. Porém se as pessoas responsáveis pela subida dos dados e indicadores não for honesta ou se houver falha quantitativa da verificação do cumprimento ou não da meta, todo o sistema vai ser alimentado com informações erradas e vai ficar comprometida a credibilidade da análise consolidada.

Outra dificuldade do sistema é dar tratamento de objetivo para algo que é Direito Humano. A linguagem de metas convida a uma "abordagem diacrônica e incremental: nós temos uma certa distância para atravessar, e assim partimos na direção do nosso destino e abordá-lo passo-a-passo" "66. Esse tipo de abordagem é imprópria em certos casos em que Direitos Humanos estão em jogo, o autor dá um exemplo marcante, se estivéssemos falando do direito humano de não ser escravizado, faria sentido traçar um plano de 25 anos com o objetivo de reduzir pela metade o número de escravos? ou de tornar a escravidão metade menos cruel?

Reconhecemos em diversos textos de Direitos $\mathrm{Hu}$ manos o direito à vida digna, dessa forma está previsto o direito humano de não ser submetido a instituições

65 DEVINFO. About DevInfo. Disponível em < http://www.devinfo.org/libraries/aspx/AboutDevInfo. aspx?'T=ADI\&PN=diorg/di_about.html $>$ Acesso em 10 de outubro de 2016.

66 POGGE, Tomas. The Hunger Games. Food ethics (2016) 1: 9. June 2016, Volume 1, Issue 1, p. 25 econômicas que façam com que milhares de pessoas previsível e evitavelmente não possam satisfazer suas necessidades básicas, fiquem doentes, tenham pior capacidade cognitiva, menor expectativa de vida e em pior qualidade. Vista sob esse prisma, a arquitetura jurídica orientada por metas e objetivos nesse caso é muito injusta, corresponde à tolerância com a morte de milhares de pessoas em virtude de doenças relacionadas à pobreza.

Para Pogge $e^{67}$, então a orientação teria de ser imediata, se a humanidade já dispõe dos meios para erradicar a pobreza extrema e a fome, seria o caso de dividir responsabilidades entre os diversos envolvidos na cadeia global de valor e de distribuição para que imediatamente houvesse a supressão total dessa intolerável violação aos Direitos Humanos. Não caberia margem de adaptação numa temática tão sensível. Para ele, a lógica de servir apenas como inspiração para futuras articulações de governança multistakeholder é muito modesta dada a crueldade do tema.

\section{Considerações finais}

Em conclusão, a relevância do presente projeto para as Relações Internacionais, como um todo e do Brasil, permeia as duas questões abordadas anteriormente. A má distribuição e a falta de acesso aos alimentos por parte da população deve ser de destaque como uma resultante da insegurança alimentar no contexto das discussões sobre o tema. Por se tratar de um tema não somente de interesse nacional, mas em nível internacional, pode-se dizer que o Brasil faz parte ao construir e colaborar com a busca da erradicação da fome e se constitui inegável a pertinência do tema, no sentido de colaborar no desenvolvimento das Relações Internacionais.

Quando desenvolvido o conceito de insegurança alimentar, infelizmente a civilização mundial teve que passar por desnecessárias Guerras Mundiais e uma enorme revolução social russa, em que 12 milhões de pessoas vieram a óbito devido à fome para que o ocidente abrisse os olhos e percebesse que a fome era uma realidade. Essa questão geopolítica foi analisada no início deste artigo e com isso foi mostrado que por isso os países conscientizaram-se sobre o problema e procuraram po-

67 POGGE, Tomas. The Hunger Games. Food ethics (2016) 1: 9. June 2016, Volume 1, Issue 1. 
líticas para que começasse uma mudança em nível global para resolve-la. Essa mudança teve sua materialização jurídica nas primeiras das conferências sediadas pela ONU para a solução do tema da insegurança ambiental em um cenário de pós-guerra. A partir desse encontro, originou-se a FAO e deram início a uma série de discussões e debates sobre medidas conjuntas para um melhor resultado para as populações subnutridas.

Para que essas medidas atingissem o seu real objetivo, a FAO teve um papel ilustre, pois fomenta até os dias atuais a realização de projetos em grande parte dos países, força para que haja debates por esse problema estar em sua agenda e faz estudos e, até mesmo, relatórios sobre o real estado da segurança alimentar nos países. Embora a FAO trabalhe no plano internacional para sanar a fome e a pobreza, ela busca a melhoria da segurança alimentar e o acesso de todos aos alimentos necessários e promove o desenvolvimento agrícola como uma estratégia para aumentar a produção de alimentos para todos, a fome vem sendo causada pela má distribuição e não por falta propriamente de alimentos.

Visto que segundo especialistas a população mundial em 2050 deve alcançar os 9 bilhões de pessoas, há uma necessidade de encontrar novas soluções para lidar com a questão da fome. Estudos, referenciados neste texto mostram que há alimento suficiente no mundo para o sustento diário de todos os habitantes do planeta e hoje existe mais comida que o necessário. A FAO reconhece que os países devem estudar e examinar o porquê de milhões de pessoas ainda passarem fome em um mundo que produz comida suficientemente para alimentar todos, assim, o problema parece ser não tanto a falta de comida, mas falta de vontade política. Sob esse panorama, a FAO desempenha diferentes funções sobre a sua atuação, cooperando e auxiliando os países no que tange a suas necessidades alimentares investindo em estudos de alimentação a partir de reuniões para estimular ações nacionais e internacionais. E sobre uma hipótese negativa, tendo em vista que é essencial uma nova redistribuição dos alimentos, e um menor desperdício, visto que uma parte da população passa fome; e outra parte são clinicamente obesos.

Por ser a temática relativa a Direitos Humanos, o modelo de governança focada em objetivos, metas e compromissos voluntários talvez não seja o ideal e precise haver algo mais contundente em termos de responsabilização dos países, dos órgãos da administração pú- blica e também da iniciativa privada. Precisa haver um esforço multistakeholder para mudança de paradigma que faça com que as instituições econômicas que ganham e perenizam o modelo capitalista atual deixem de fazer com que milhares de pessoas previsível e evitavelmente não possam satisfazer suas necessidades básicas, fiquem doentes, tenham pior capacidade cognitiva, menor expectativa de vida e em pior qualidade.

A luta pela erradicação da fome é um desafio ético estrutural que só pode ser vencido com alterações sistêmicas do modelo econômico vigente. Medidas mitigatórias tímidas, condenam milhões à morte, à doença ou à falta de qualidade de vida e portanto precisam ser substituídas e fomentadas por políticas mais eficazes e arrojadas. O modelo de metas adotado pela Agenda do Milênio e agora pela Agenda 2030 geram resultados positivos, mas muito aquém do necessário.

\section{ReferênCiAs}

AMIN, S.; PATEL, R.; SCHUTTER, O. D.; STEDILE, J. P. Food Movements Unite!: Strategies to Transform Our Food System (E. Holt-Gimenez, Org.). Oakland, CA: Food First Books, 2011.

BEURLEN, Alexandra. Direito humano à alimentação adequada no Brasil. 3.ed. Curitiba: Juruá, 2008.

BUZAN, B.; WVER, O.; WILDE, J. D. Security: A New Framework for Analysis. Boulder, Colo: Lynne Rienner Pub, 1997.

CASTRO, Josué de. Geografia da fome: o dilema brasileiro: pão ou aço. 10. ed. Rio de Janeiro: Antares, 1983.

COSTA, Claudia V.; BEGNIS, Heron Sergio M. Revista de Economia \& Relações Internacionais. Fome mundial: uma análise de suas causas e da atuação da FAO. Vol. 12(24), pp. 44-60, 2014.

DEVINFO. About DevInfo. Disponível em < http:// www.devinfo.org/libraries/aspx/AboutDevInfo. aspx?T=ADI\&PN=diorg/di_about.html $>$ Acesso em 10 de outubro de 2016.

FAO, WFP and IFAD (Food and Agriculture Organization of the United Nations, World Food Programme and International Fund for Agricultural Development). 2012. The state of food insecurity in the world 2012. Rome: FAO, 2012. Disponível em: < http://www.fao. 
org/docrep/016/i3027e/i3027e.pdf>. Acesso: 20 outubro 2016.

FAO, WFP and IFAD (Food and Agriculture Organization of the United Nations, World Food Programme and International Fund for Agricultural Development). The state of food insecurity in the world 2015. Rome: FAO, 2015. Disponível em: < http://www.fao.org/3/ a4ef2d16-70a7-460a-a9ac-2a65a533269a/i4646e.pdf> . Acesso: 20 outubro 2016.

FAO. Declaração de Roma sobre segurança alimentar mundial. Disponível em: <http://www.fao. org/wfs/>. Acesso: 20 outubro 2016.

FAO. Organização das Nações Unidas para a Alimentação e a Agricultura. O desperdício alimentar tem consequências ao nível do clima, da água, da terra e da biodiversidade - novo estudo da FAO. Roma, 2013. Disponível em: <http://www.fao.org/news/ story/pt/item/204029/icode/>. Acesso: 20 outubro 2016.

FAO. Organização das Nações Unidas para a Alimentação e a Agricultura. Food wastage footprint: Impacts on natural resources. 2013. Disponível em: <http://www.fao.org/docrep/018/i3347e/i3347e. pdf>. Acesso: 20 outubro 2016.

FIEP. Portal ODM. Disponível em < http://www.portalodm.com.br > Acesso em 10 de outubro de 2016.

KEARNS, Antony P. The Right to Food Exist via Customary Internacional Law. Suffok Transnational Law Review. Vol.22, n.1, pp. 223-257,1998-1999.

KEOHANE, Robert O.; NYE, Joseph. Power and Interdependence: World Politics in Transition. Nova York: Longman, 2001.

LEÃO, Marília (Org.). O Direito Humano à Alimentação Adequada e o Sistema nacional de Segurança Alimentar e Nutricional. Brasília: ABRANDH, 2013. MRE, Ministério das Relações Exteriores. Banco Mundial. [s/d]. Disponível em: <http://www.itamaraty.gov. $\mathrm{br} / \mathrm{pt}-\mathrm{BR} /$ politica-externa/diplomacia-economica-comercial-e-financeira/120-banco-mundial>. Acesso em: 01 jun. 2016.

MÜLLER, Marcela. Direito fundamental à alimentação adequada no contexto das organizações internacionais. Curitba: Juruá, 2014.

NUNES, Mérces da Silva. O direito fundamental à alimentação: e o princípio da segurança. Rio de Janeiro: Elseiver, 2008.

ONU. The Millennium Development Goals Report. 2015. Disponível em: < http://www.un.org/millenniumgoals/2015_MDG_Report/pdf/MDG\%20 2015\%20rev\%20(July\%201).pdf > Acesso: 20 de outubro de 2016

PEARSON, Craig. A fresh look at the roots of food insecurity. In: RAYFUSE, Rosemary; WEISFELT, Nicole (Orgs.). The challenge of food seccurity: internacional policy and regulatory frameworks. Cheltennham, UK: Edward Elgar, 2012.

PIOVESAN, Flávia. Direitos humanos e o direito constitucional internacional. $13^{\circ}$ ed, p.6. São Paulo: Saraiva, 2007.

POGGE, Thomas e MEHTA, Krishen. Global tax fairness. Nova York: Oxford University Press, 2016, p. 291.

POGGE, Tomas. The Hunger Games. Food ethics (2016) 1: 9. June 2016, Volume 1, Issue 1, pp 9-27 Disponível em: < http://link.springer.com/ article/10.1007\%2Fs41055-016-0006-9\#aboutarticle > Acesso em 10 de outubro de 2016

SHAW, D. World Food Security: A History since 1945. 2007 edition ed. Basingstoke England ; New York: Palgrave Macmillan, 2007

SHIVA, V. Monoculturas Da Mente. Perspectivas Da Biodiversidade E Biotecnologia. São Paulo: Gaia, 2003; CARSON, R. Primavera silenciosa. Editora Gaia, 2015.

SISAN. Sistema Nacional de Segurança Alimentar e Nutricional. Sistema Nacional de Segurança Alimentar e Nutricional. Brasília, 2003. Disponível em: <http:/ / www4.planalto.gov.br/consea/acesso-a-informacao/ institucional/conceitos/sistema-nacional-de-seguranca-alimentar-e-nutricional>. Acesso em: 07 jun. 2016.

VALENTE, Luiz Schieck. Direito Humano à Alimentação: desafios e conquistas. São Paulo: Cortez, 2002.

VILLA, R. D. Multidimensional global security. Lua Nova: Revista de Cultura e Política, , n. 46, p. 99118. doi: 10.1590/S0102-64451999000100005, 1999.

ZIEGLER, Jean. Destruição em massa: Geopolítica da fome. São Paulo: Cortez, 2013. 
Para publicar na Revista de Direito Internacional, acesse o endereço eletrônico www.rdi.uniceub.br ou www.brazilianjournal.org.

Observe as normas de publicação, para facilitar e agilizar o trabalho de edição. 